\title{
SIMPLIFIED DESIGN EQUATION FOR WEB TAPERED - I - SECTIONS USING FINITE ELEMENT MODELING
}

\author{
C.RAMESHBABU ${ }^{1}$ S.PRABAVATHY ${ }^{2}$
}

\begin{abstract}
The web - tapered I-columns have the capacity to resist the flexural buckling and lateral torsional buckling at a particular location where as in the rest of the member the capacity is lower. There needs a focusing on the nonprismatic members, to find the buckling capacity and standard procedures are to be framed in Indian Code IS 800:2007. This exploratory research explores simulated finite element models covering a total of 60 web tapered column sections having taper ratios $\left(\mathrm{h}_{2} / \mathrm{h}_{1}\right)$ from 1.0 to 3.0 using FEA software ANSYS17.2. With an elaborate Eigenvalue buckling analysis, this research has come up with newer design equation for calculating the buckling load of web tapered I columns. This novel equation could predict the buckling stress for any taper ratio of web tapered I column of any length.

Keywords: Web taper, I Section, Eigen value buckling, Finite Element Modelling, Ansys,
\end{abstract}

\section{INTRODUCTION}

The construction industry and the steel manufacturers world-wide currently focus on material savings, optimization and economic design with the advent of three dimensional printing technologies. The tapered steel members had been on use from 1960s as reported [1] and the design provisions had been conservative in the era of computational solutions devoid of computers. Joint Task Committee was triggered [1] forming Column Research Committee and Council and Welding Research Council

\footnotetext{
${ }^{1}$ PhD Scholar \& Assistant Professor (Sr.Gr.), Department of Civil Engineering, Mepco Schlenk Engineering College, Sivakasi, India 626005, email: rameshbabu_1979@rediffmail.com

${ }^{2}$ Head of the Department, Department of Civil Engineering, Mepco Schlenk Engineering College, Sivakasi, India 626005, email:spraba@mepcoeng.ac.in
} 
during 1966. The tapered structural elements were tested to destruction in olden days of research for obtaining the bending and buckling strength adjusting the boundary conditions such that failure was made to occur within the elastic limit. These testing programs were the continuity of welding[2] research. The research history on fabrication of Tapered I sections during 1960s were usually of two different kinds i.e., Plates cut by shearing process and Oxygen cut plates. The past research concludes that the buckling effect was more pronounced when the angle of taper was larger. Non uniform tapered sections are more efficient than the prismatic sections and could be used in frequent where major axis bending varies along the beam length [2]. The flexural rigidity and torsional rigidity are vulnerable in narrow rectangular structural elements, whereas the reverse occurs in case of web tapered I columns and beams having no significance on minor flexural rigidity, with vulnerability limited to warping rigidity. Closed form solutions [3] are available for non-prismatic tapered I sections. Varied numerical methodologies had been quoted for calculating the elastic buckling loads of tapered I sections with solutions [3 - 7]. Tapered members provide structural efficiency and aesthetic appearance and find applications in industrial halls, ware houses and exhibition centres. In the scope of member design [8] taper ratio $\left(\mathrm{h}_{2} \mathrm{~h}_{1}\right)$ of 4 cover a larger proportion of existing structure. There has been a global objective for economical, affordable and faster fabrication in steel construction industry say industrial sheds, trusses, bridges, multistorey buildings, factory buildings, dwelling units and the prefabricated units. The tapered members have wider application in steel industry [8] due to their structural efficiency that led to material savings and light weight. This would pave way for aesthetics, along with modest fabrication expenses with the advent of $3 \mathrm{D}$ printing. The web tapered I sections have an outstanding capacity to resist the flexural buckling and lateral torsional buckling at a particular location where as in the rest of the member the capacity is lower or not required in technicality aspect. The Indian Steel Code IS 800:2007 [12] is silent regarding the web tapered non prismatic members. Liliana [9] narrates that EC3 has provided codal provisions for verifying structural stability of elements and frames fabricated with prismatic members. However in case of non-prismatic members with tapers and castellation, the behaviour needs to be fully understood and codified further. There had been many proposals and derivations from researchers to find the buckling capacity of web tapered I beams and columns. But [9] all the theories urge calculations, based on tedious non-linear buckling analyses and iterations. Few researchers [9] adopted evaluating critical buckling load of tapered I columns using Rayleigh Ritz approach. However, the differences up to $8 \%$ had been noted when compared with Linear Buckling Analysis Model. Rahai , [10] the researcher had revealed a new procedure for performing the buckling analysis of tapered column members. The research proposed to include a tapering index in the formula for estimating critical buckling load. The linear combination of various modes of prismatic cross sections 
were used for finding mode shapes of tapered columns. Also the finding observed an enhancement in the critical buckling loads by appropriately distributing the moment of Inertia along the length. Ioannis , [11] analysed the critical lateral torsional buckling moments of web tapered I beams. The tapered I beams were explored for stability analysis. The investigations revealed that the tapered beams carried maximum moment at a single location. Also the scientist narrates that numerous studies had focussed on the behaviour of tapered beams with in the elastic limit. The outcome of the research exposed theoretical findings that could be incorporated in codal provisions. Slope deflection was used for predicting the buckling capacity of tapered bar elements under flexure and axial force. Also flexural torsional buckling under transverse loads and axial loads were researched. All the research works finally concluded that the stability analysis is a must for designing the web tapered I beams or columns. The research also recommended that the taper ratio $\left(\mathrm{h}_{2} / \mathrm{h}_{1}\right)$ had a significant influence on finding the critical load of web tapered I beams particularly the cantilevers. The $\mathrm{h}_{2}$ stands for depth of the "I" column at the fixity. The $\mathrm{h}_{1}$ stands for the depth of I section at the top of the column $\left(h_{2}>h_{1}\right)$. This paper narrates the development of design equation for predicting the critical buckling load of web tapered I sections used as columns. The tapering ratios were varied as 1, 1.5, 2, 2.5 and 3.0. This research is confined to Eigenvalue buckling analysis of web tapered I column sections using ANSYS 17.2. The role of taper ratio on the critical buckling capacity (Euler's buckling load) had been thoroughly studied. A total of $60 \mathrm{web}$ tapered column sections covering 5 taper ratios $\left(\mathrm{h}_{2} / \mathrm{h}_{1}\right)$ from 1.0 to 3.0 has been simulated in ANSYS17.2 using shell elements (SHELL 63) and their critical buckling stress had been arrived. The buckling behaviour had been limited to three types of lengths namely $6 \mathrm{~h}, 7 \mathrm{~h}$ and $8 \mathrm{~h}$ which had not been covered in the past investigations.( $\mathrm{h}_{1}$ represents depth of the I section at the top) The boundary conditions were assumed to have fixity at one end and free at the other end. The most vulnerable boundary conditions were adopted. It has been found from the research that the taper ratio significantly impacts the critical buckling stress of the web tapered columns. The results are presented in graphical form and finally the research came up with newer expression for finding the critical buckling stress for web tapered column sections.

\section{WEB TAPERED I SECTIONS}

\subsection{INDIAN STANDARD I SECTIONS:}

The Indian standard sections chosen for this research are (Indian Standard Medium Weight Beam) ISMB 200, ISMB 300, ISMB 350 and ISMB 400. For each "I" section 5 taper ratios were adopted for the simulations having lengths $6 \mathrm{~h}, 7 \mathrm{~h}$ and $8 \mathrm{~h}$. The properties of the sections were referred from 
SP 6 - 1 (1964) [13] (Hand Book for Structural Engineers). The chosen sections were prismatic standard sections from the handbook and at the other end the properties were based on the corresponding slenderness ratios. The medium weight "I" beam sections were chosen for this pilot study and pure research was executed.

\subsection{SIMULATION OF WEB TAPERED I SECTIONS USING ANSYS 17.2}

The web tapered columns were simulated by using SHELL63 elements. This SHELL 63 has both bending and membrane capabilities. Both in-plane and normal loads are permitted. The element has six degrees of freedom at each node: translations in the nodal $\mathrm{x}, \mathrm{y}$, and $\mathrm{z}$ directions and rotations about the nodal $\mathrm{x}, \mathrm{y}$, and z-axes. Stress stiffening and large deflection capabilities are included. A consistent tangent stiffness matrix option is available for use in large deflection (finite rotation) analyses. The figure 12 shows the description of SHELL 63 element. The tapered columns were simulated by having same flange thickness $\left(t_{f}\right)$, web thickness $\left(t_{w}\right)$ but having different taper ratios $\left(h_{2} / h_{1}\right)$. As shown in figure 1, the shell element had 4 nodes where each node was assigned the same thickness. The mapped meshing using SHELL 63 elements was defined with two thicknesses representing $t_{f}$ and $t_{w}$. The SHELL elements with two set of real constants, one for the web thickness and another for flange thickness had been adopted. Skinning methodology was adopted in simulation of all tapered columns. The properties of steel were assigned to the material model. The figure 2 denotes the simulated web tapered I section which depicts the constraints at the bottom (Fixed support) and application of loading at the top. The web taper could be seen in the above figure. The simulation was possible after creating key points and lines. Skinning of the lines led to the $2 \mathrm{D}$ simulation. After meshing the web and the flanges, the common nodes were merged to maintain continuity and the simulated model the represented the tapered I column. The Eigenvalue buckling analysis was then carried out which yielded the buckling strength of the columns.

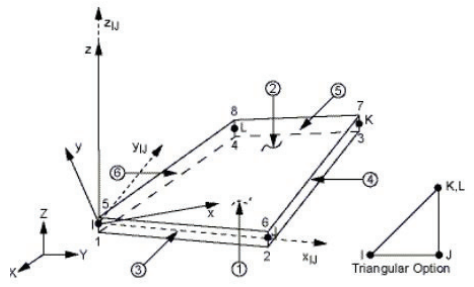

Figure 1 SHELL 63 Element

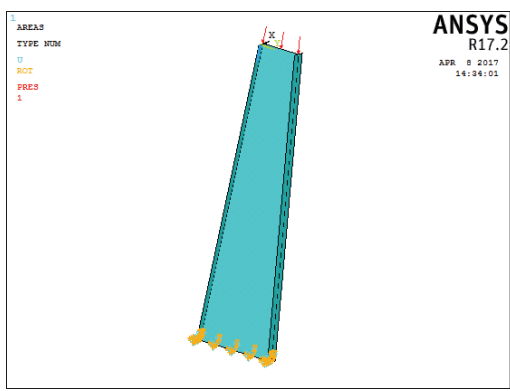

Figure 2 Loads and Constraints 


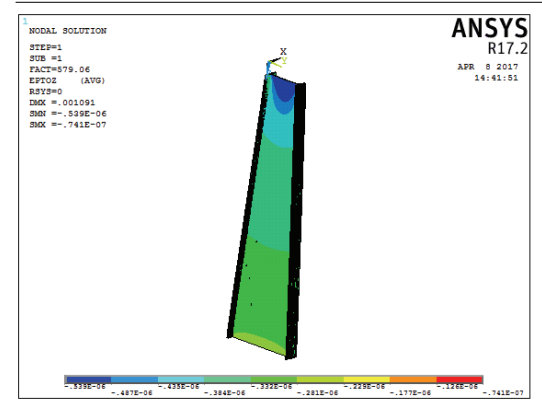

Figure 1 Strain Plot for ISMB 400

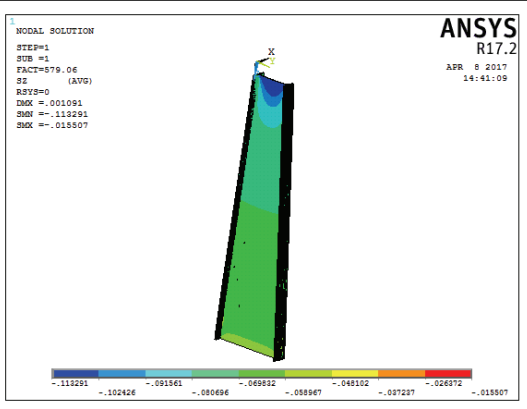

Figure 4 Stress Plot for ISMB 400

The figure 3 shows the strain plot of ISMB 400. At the top the value being 0.539 e- 4 while $0.741 \mathrm{e}-7$ was observed at the bottom. The figure 4 represents the maximum stress getting developed at the bottom where the fixity condition was observed the value being $-0.0155 \mathrm{MPa}$. The Eigenvalue buckling analysis through ANSYS17.2 could give load factor as 579.04 for ISMB 400. The above plots shown in both the figures are the sample plots representing the analysis using FEA software and the same kind of simulation was adopted for other sections also.

\section{RESULTS AND DISCUSSIONS}

The Eigen value analysis had been carried out for ISMB200, ISMB 300, ISMB 350, ISMB 400. Each tapered I column had 5 taper ratios $(1.0,1.5,2.0,2.5,3.0)$ and having slenderness ratio $(6 \mathrm{~h}, 7 \mathrm{~h}$ and $8 \mathrm{~h})$. Hence for the five sections, about 60 specimens had been simulated. The following tables and graphical plot is the summary of the research work evaluated. The critical load ratio $f_{\mathrm{cr}} / \mathrm{f}_{\mathrm{co}}$ has been plotted against the taper ratios of the respective columns for different $\mathrm{L} / \mathrm{h}$ ratios.

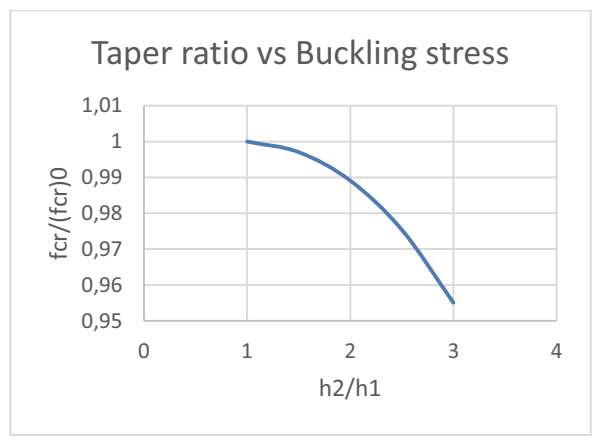

Figure 5 ISMB 200 (1=6h)

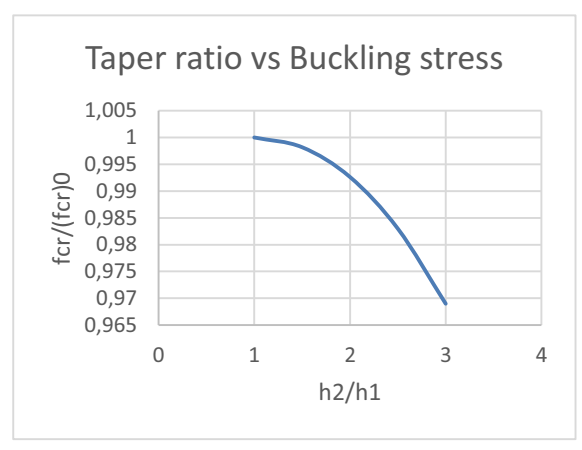

Figure 6 ISMB $200(1=7 h)$ 


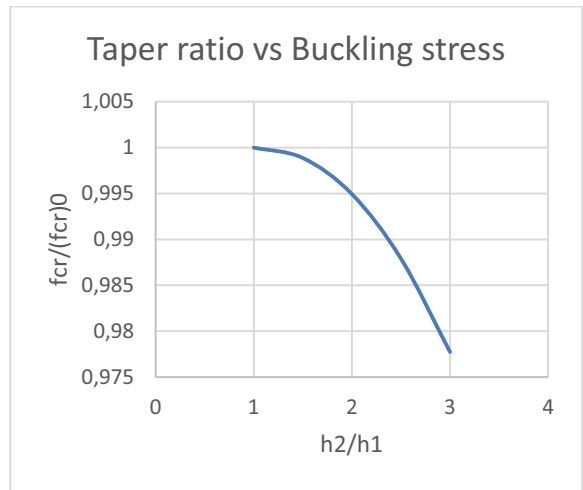

Figure 7 ISMB 200 (l=8h)

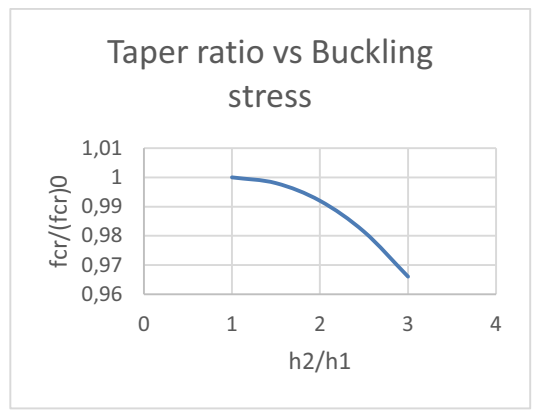

Figure 9 ISMB $300(1=7 \mathrm{~h})$
Taper ratio vs Buckling stress

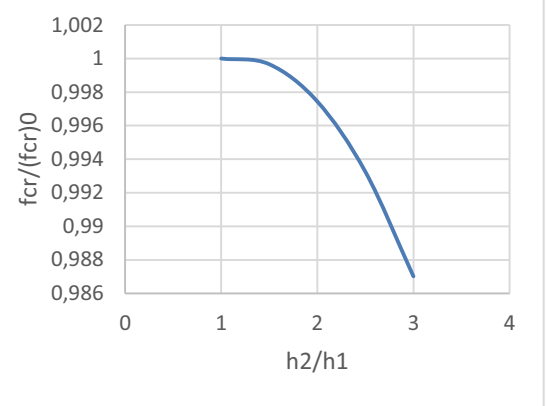

Figure 8 ISMB 300 (l=6h)

Taper ratio vs Buckling stress

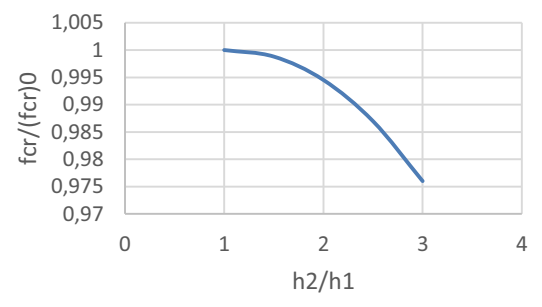

Figure 10 ISMB 300 (l=8h)

The figures 5- 7 represent the buckling stress versus taper ratio for ISMB 200. The $\mathrm{f}_{\text {cr }}$ represents the critical buckling stress of the tapered section due to Eigenvalue Buckling analysis on tapered section. The $\mathrm{f}_{\text {cro }}$ denotes the buckling stress for the prismatic column made of ISMB 200. The graphical plot could show that there is a drop in the buckling stress as well as buckling load as the length of the tapered column increases. A drop of $4 \%$ was observed in ISMB 200 from the length of $6 \mathrm{~h}, 3.1 \%$ for $\mathrm{L}=7 \mathrm{~h}$ and $2.2 \%$ for $\mathrm{L}=8 \mathrm{~h}$. The $4 \%$ drop is in consistent with the values observed by Ioannis G.Ratoyiannis et. al [3] for lengths greater than $6 \mathrm{~h}$. 
Taper ratio vs Buckling stress

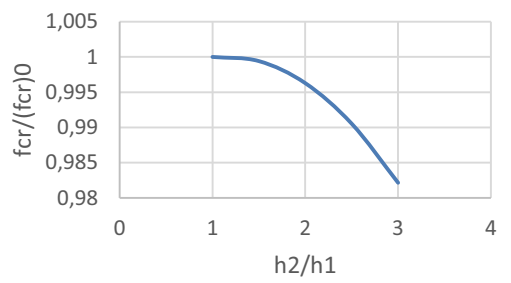

Figure 11 ISMB $350(1=6 h)$

\section{Taper ratio vs Buckling stress}

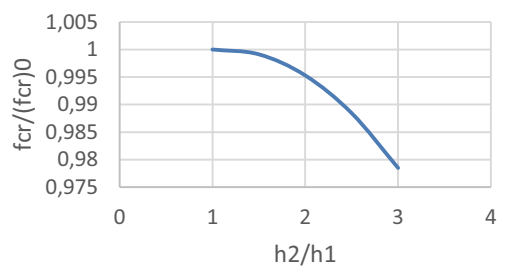

Figure 13 ISMB $350(\mathrm{l}=8 \mathrm{~h})$
Taper ratio vs Buckling stress

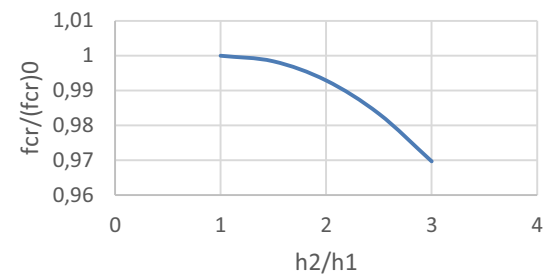

Figure 12 ISMB $350(1=7 h)$

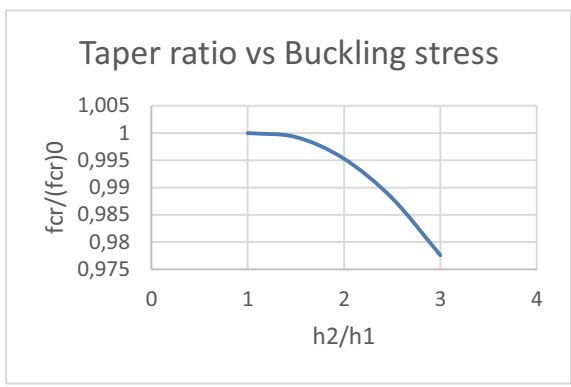

Figure 14 ISMB $400(1=6 h)$

For ISMB 300 represented by figures $8-10$, the drop in buckling stress was $1.2 \%$ for $\mathrm{l}=6 \mathrm{~h}, 3.4 \%$ for $1=7 \mathrm{~h}$ and $2.4 \%$ for $1=8 \mathrm{~h}$. For ISMB 350 the taper ratio versus critical buckling stress ratio plot is depicted in figures $11-13$. The drop in buckling stress was $1.7 \%, 3.0 \%$ and $2.1 \%$ for $\mathrm{L}=6 \mathrm{~h}, \mathrm{~L}=7 \mathrm{~h}$ and $\mathrm{L}=8 \mathrm{~h}$ respectively. Similarly the figures $14-16$ represent a drop of $2.2 \%, 2.68 \%$ and $1.8 \%$ for lengths ranging from $L=6 h$ to $L=7 h$.

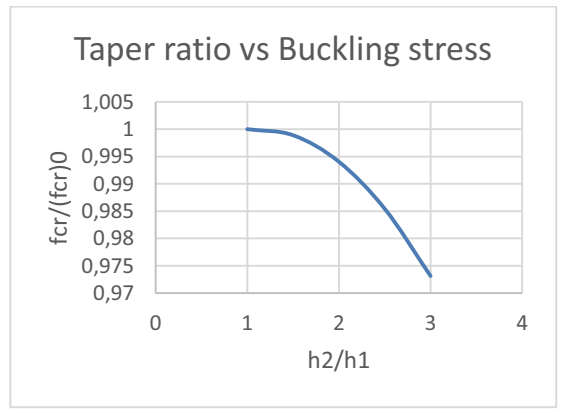

Figure 15 ISMB $400(7 \mathrm{~h})$

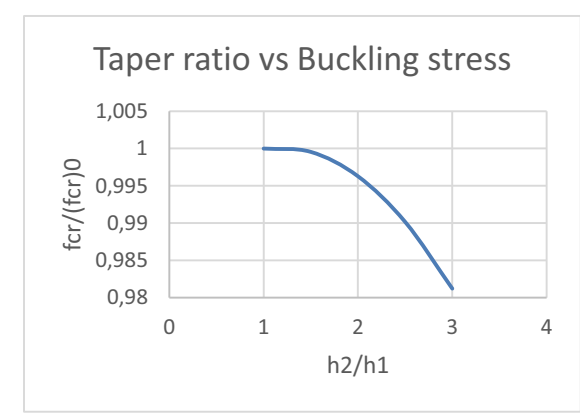

Figure 16 ISMB $400(1=8 \mathrm{~h})$ 
The graphical plots have led to the following curve fit depicted in the table 1. Table 1 Equations stating the relation between the buckling stress ratio and the taper ratio

Table 1 Relation between buckling stress and taper ratio

\begin{tabular}{|l|l|l|l|}
\hline ISMB 200 & $\mathbf{6 h}$ & $\mathbf{7 h}$ & $\mathbf{8 h}$ \\
\cline { 2 - 4 } & $\frac{f_{c r}}{f_{c o}}=1.007\left(\frac{h_{2}}{h_{1}}\right)^{-0.038}$ & $\frac{f_{c r}}{f_{c o}}=1.005\left(\frac{h_{2}}{h_{1}}\right)^{-0.0268}$ & $\frac{f_{c r}}{f_{c o}}=1.004\left(\frac{h_{2}}{h_{1}}\right)^{-0.02}$ \\
\hline ISMB 300 & $\frac{f_{c r}}{f_{c o}}=1.0023\left(\frac{h_{2}}{h_{1}}\right)^{-0.011}$ & $\frac{f_{c r}}{f_{c o}}=1.0056\left(\frac{h_{2}}{h_{1}}\right)^{-0.029}$ & $\frac{f_{c r}}{f_{c o}}=1.004\left(\frac{h_{2}}{h_{1}}\right)^{-0.0206}$ \\
\hline ISMB 350 & $\frac{f_{c r}}{f_{c o}}=1.0031\left(\frac{h_{2}}{h_{1}}\right)^{-0.053}$ & $\frac{f_{c r}}{f_{c o}}=1.0051\left(\frac{h_{2}}{h_{1}}\right)^{-0.026}$ & $\frac{f_{c r}}{f_{c o}}=1.0037\left(\frac{h_{2}}{h_{1}}\right)^{-0.018}$ \\
\hline ISMB 400 & $\frac{f_{c r}}{f_{c o}}=1.004\left(\frac{h_{2}}{h_{1}}\right)^{-0.019}$ & $\frac{f_{c r}}{f_{c o}}=1.004\left(\frac{h_{2}}{h_{1}}\right)^{-0.017}$ & $\frac{f_{c r}}{f_{c o}}=1.003\left(\frac{h_{2}}{h_{1}}\right)^{-0.016}$ \\
\hline
\end{tabular}

The table 1 represents the relation between buckling stress and the taper ratio for all the sections starting from ISMB200 to ISMB 400. The trend does not show much variation in all the cases. The differences between all the equations could be negligible. The variation is assumed to be parabolic and the convergence point is almost same for all the tapered columns whose properties were taken from SP (6). Based on the above observation, the following equation is derived which is a simplified one for predicting the buckling load for tapered "I"sections. The buckling stress could be used to find the critical buckling load as represented in equation 2 .

$$
\begin{aligned}
f_{c r} & =1.0023 \frac{\pi^{2} E}{(1000 \lambda)^{2}}\left(\frac{h_{2}}{h_{1}}\right)^{-0.011} \\
\mathrm{P}_{\text {cr }} & =\mathrm{f}_{\text {cr }} \mathrm{X} \mathrm{A}_{1}
\end{aligned}
$$

Eq-1

$\mathrm{Eq}-2$

Where $\mathrm{E}=$ Young's modulus of Elasticity

$$
\begin{aligned}
& \lambda=\text { The slenderness ratio based on the corresponding I section } \\
& \mathrm{h}_{2}=\text { Depth of the I section at the base } \\
& \mathrm{h}_{1}=\text { Depth of the I section at the top } \\
& \mathrm{P}_{\mathrm{cr}}=\text { Critical Buckling load of tapered section } \\
& \mathrm{A}_{1}=\text { Area at the top of the tapered I column }
\end{aligned}
$$

\section{CONCLUSIONS}

1. An extensive analytical study had been depicted based on the FEA using SHELL 63 elements in ANSYS 17.2. The element was apt and feasible for the buckling analysis. The inbuilt direct matrix abstraction program adopted "Block Lancos" algorithm for linear buckling analysis in 
the FEA software. The prestressing effect was initiated in arriving the buckling load using single mode. About 60 specimens of web tapered I sections has been simulated using SHELL 63 elements.

2. The slenderness ratio has minor influence in predicting the buckling stress. The height of the web does not have much impact in the buckling stress and a linear negligible variation was observed.

3. The taper ratio has found to significantly control the buckling stress and as the taper ratio increases, the buckling stress ratio drops [14] as stated by EC3-1-1.

4. The research came up with a simple formula for the calculation of critical Euler's load for tapered I columns based on the buckling stress from Eigenvalue buckling analysis.

5. The formula is adequate for the evaluation of critical stress for the non-prismatic web tapered sections. The accuracy of the formula was evaluated based on past research predictions stated by Ioannis G. Raftoyiannis [4]. The values are exact when compared with the above formulae which is conservative. The finite element modeling could pronounce the critical buckling load. Among all the complicated procedures to evaluate the buckling stress, this research has simplified the application and formulation for web tapered columns.

\section{REFERENCES}

1. Prawel.S.P., Morrell .M.L.Lee. G.C, „, Bending and Buckling Strength of Tapered Structural Members“, Journal of Experimental Mechanics, Feb 1984.

2. Butler .D.J., and Anderson G.B.,“ The Elastic Buckling of Tapered Beam Columns“, Welding Journal Vol 42. No.1 (Jan 1963)

3. Kitipornchai.S. et.al.,"Elastic Stability of Tapered I - Beams“ Journal of Structural Division ASCE 98 No. ST3, pp. 713-28.

4. Nethercot, D.A. Lateral buckling of tapered beams, Publications, IABSE, 33, pp. 173-92. (1973)

5. Bradford, M.A. and Cuk, P.E. Elastic buckling of tapered monosymmetric I-beams, Journal of Structural Engineering, ASCE, 114, No. 5, pp. 977-96. (1988)

6. Kitipornchai, S., andTrahair, N.S. Elastic behaviour of tapered monosymmetric I-beams, Journal of the Structural Division, ASCE, 101, No. ST8, pp. 1661-78. (1975)

7. Bradford, M.A.“Inelastic buckling of tapered monosymmetric I-beams, Engineering Structures“ 11, No. 2, pp. 119-126. (1989)

8. Anisio Andrade et.al." "Lateral Torsional buckling of singly symmetric web - tapered thin walled I beams : 1D Model vs Shell FEA” Computers and Structures, 85 pp. 1343 - 1339, 2007

9. Liliana Marques et. Al., "Rayleigh Ritz procedure for the determination of the critical load of tapered columns" , Steel and Composite Structures, Vol 16 No.1 pp 45-58 (2014)

10. A.R.Rahai et. al.,"Buckling Analysis of non-prismatic columns based on modified vibration modes", Communication in Nonlinear Science and Numerical Simulation, 13 , pp 1721-1735 (2008)

11. Ioannis G. Raftoyiannis et. al.,"Critical lateral - Torsional Buckling Moments of Steel Web - Tapered I Beams”, The open Construction and Building Technology Journal, 4, pp 105-1122010 (2010)

12. IS 800: 2007, Indian Standard General Construction In Steel — Code Of Practice

13. SP: 6 - (1) 1964, Handbook for Structural Engineers

14. Eurocode 3 - Design of steel structures - Part 1-3: General rules - Supplementary rules for cold-formed members and sheeting. 


\section{List of Figures and Tables}

Figure 1 SHELL 63 Element

Figure 2 Loads and Constraints

Figure 3 Strain Plot for ISMB 400

Figure 4 Stress Plot for ISMB 400

Figure 5 Taper ratio vs Buckling Stress ISMB $200(\mathrm{l}=6 \mathrm{~h})$

Figure 6 Taper ratio vs Buckling Stress ISMB $200(\mathrm{l}=7 \mathrm{~h})$

Figure 7 Taper ratio vs Buckling Stress ISMB $200(\mathrm{l}=8 \mathrm{~h})$

Figure 8 Taper ratio vs Buckling Stress ISMB $300(\mathrm{l}=6 \mathrm{~h})$

Figure 9 Taper ratio vs Buckling Stress ISMB $300(\mathrm{l}=7 \mathrm{~h})$

Figure 10 Taper ratio vs Buckling Stress ISMB 300 (l=8h)

Figure 11 Taper ratio vs Buckling Stress ISMB 350 (l=6h)

Figure 12 Taper ratio vs Buckling Stress ISMB $350(1=7 \mathrm{~h})$

Figure 13 Taper ratio vs Buckling Stress ISMB 350 (l=8h)

Figure 14 Taper ratio vs Buckling Stress ISMB 400 (l=6h)

Figure 15 Taper ratio vs Buckling Stress ISMB $400(1=7 \mathrm{~h})$

Figure 16 Taper ratio vs Buckling Stress ISMB 400 (l=8h)

Table 1 Relation between buckling stress and taper ratio

\section{Notations and Symbols}

ISMB 200 : Indian Standard Medium Weight Beam with a depth of $200 \mathrm{~mm}$.

ISMB 300 : Indian Standard Medium Weight Beam with a depth of $200 \mathrm{~mm}$.

ISMB 350 : Indian Standard Medium Weight Beam with a depth of $200 \mathrm{~mm}$.

ISMB 400 : Indian Standard Medium Weight Beam with a depth of $200 \mathrm{~mm}$.

$\mathrm{f}_{\mathrm{cr}} \quad$ : Critical Buckling Stress of Web Tapered "I" Column

$\mathrm{f}_{\mathrm{cr} 0} \quad$ : Critical Buckling stress of prismatic "I" Column

$\mathrm{h}_{2} \quad$ : Depth of the Tapered column at the bottom edge

$\mathrm{h}_{1} \quad$ : Depth of the Tapered column at the top edge

$1 \quad$ : Length of the Column

E : Young's modulus of Elasticity of Steel of grade Fe 415

$\lambda \quad:$ The slenderness ratio based on the corresponding I section

$\mathrm{P}_{\mathrm{cr}} \quad$ : Critical Buckling load of tapered section

$\mathrm{A}_{1} \quad$ : Area at the top of the tapered I column 